\title{
Attitude towards Research among Nurses: An Evaluatory Study
}

\author{
Amita Devrani', AD Chaudhuri' ${ }^{2}$, jilmy Anu Jose ${ }^{3}$
}

${ }^{1}$ Professor and Principal, M.Sc. Child Health Nursing, College of Nursing, Army Hospital Research and Referral, New Delhi, India.

${ }^{2,3}$ Associate Professor, M.Sc. Medical Surgical Nursing, College of Nursing, Army Hospital Research and Referral, New Delhi, India.

DOI: https://doi.org/10.24321/2455.9318.201830

\begin{abstract}
Research is a vital aspect of all health services and essential to the provision of effective and safe health care. The scope of nursing research is to strengthen the body of knowledge in nursing practice, education and administration. A cross-sectional evaluatory study was conducted among 50 registered nurses from a Quaternary Care Centre in Delhi NCR in 2017 to evaluate the attitude of Nurses towards research. The tool consisted of an attitude scale with 20 items. The analysis of data revealed that majority of the Nurses (84\%) had positive attitude towards research whereas $16 \%$ were neutral towards research. No nurses were found to have a negative attitude. It was also found that only $14 \%$ presented paper in conference and $12 \%$ nurses published articles in journal. No significant associations were found between attitude and professional qualification, attitude and research publication with the Chi square value of 0.0023 and 1.0582 respectively. This study reflects that in spite of having positive attitude towards research, very minimal number of nurses is participating in any form of research work as only $10 \%$ of nurses conducted individual researches in their area of work. The study concluded that there is a need to motivate nurses to conduct clinical researches in their area of work and to disseminate the information through publications and presentations.
\end{abstract}

Keywords: Attitude, Nurse, Research

\section{Introduction}

Nursing is the largest, the most diverse, and one of the most respected of all the health care professions. Over a period of time nursing has seen continuous growth and expansion of vast amount of knowledge through research. Research is a vital aspect of all health services and essential to the provision of effective and safe health care. The ultimate aim of nursing profession is to provide quality care to the clientele which is possible by evidence-based nursing care. Nursing, as a scientific discipline requires its knowledge to be driven by the findings of research. The general purpose of nursing research is to answer questions or solve problem. The specific purpose of nursing research includes identification, descriptions, exploration, explanation, prediction and control of facts. ${ }^{1}$
The scope of nursing research is to strengthen the body of knowledge in nursing practice, education and administration. With the development of advanced medical technology, at present the trend is to conduct clinical researches with an aim to develop evidence for nursing practice. Nurses' research utilization as part of evidencebased practice is strongly emphasized in today's nursing education and clinical practice. The primary aim of research utilization is to provide high-quality nursing care to patients.

Research is now part of the nurses' professional role and responsibility that has been intertwined with concepts of efficiency, effectiveness and quality improvement in health care. In India, as in most developing countries, increasing cost limitations, a push for quality of clinical care, and patient-centered care are some of the forces that require

Corresponding Author: Jilmy Anu Jose, M.Sc. Medical Surgical Nursing, College of Nursing, Army Hospital Research and Referral, New Delhi, India.

E-mail Id: jilmyanujose@gmail.com

Orcid Id: https://orcid.org/0000-0003-0820-6436

How to cite this article: Devrani A, Chaudhuri AD, Jose JA. Attitude towards Research among Nurses: An Evaluatory Study. Int J Nurs Midwif Res 2018; 5(3): 41-44. 
health care to be based on scientific research. ${ }^{2}$ Today's nurses is often weighed down with a variety of competing priorities. Finding time and resources to conduct research as a nurse clinician can be challenging.

Florence Nightingale, the Founder of Modern Nursing proved to the world that research methodology especially careful data collection can help nurses to analyze and solve the problem to improve quality of patient care. Recognizing the importance of nursing research, the Indian Nursing Council has included research and statistics as a full subject from a very basic level of nursing education i.e. General Nursing \& Midwifery from the year 2002. Research is being conducted as partial fulfillment of the undergraduate and postgraduate degree program in Nursing. Indian Nursing Council has established National Consortium for PhD in Nursing in Collaboration with Rajiv Gandhi University of Health Sciences Bangalore to promote Nursing research from the year 2005. In the year 2009 Indira Gandhi National Open University (IGNOU) started PhD in Nursing in India.

Inspite of adequate academic exposure of research in all nursing educational program there is lack of initiatives from the nurses to take part in research activities. Research suggests that the barriers preventing nurses from undertaking their own research include lack of time, confidence, motivation, support and knowledge, as well as low staffing levels and negative attitudes to research. ${ }^{3}$

Bjorkstrom ME and Hamrin EK conducted a study ${ }^{4}$ to evaluate Swedish nurses' attitudes towards research and development within nursing. The results indicated that the respondents in general had positive attitudes towards nursing research. $46 \%$ never or seldom utilized nursing research findings in their daily practice. About $50 \%$ of the respondents never read research reports. Even if the respondents had a positive attitude towards research and development, there was a poor application in their daily work.

Poreddi V et al. conducted a Quantitative cross-sectional study in the year 2014 to examine nurses' attitudes and perceptions towards nursing research. ${ }^{5}$ The findings of the study revealed that nurses had fairly positive attitude in research usefulness. Result further revealed that $38.7 \%$ felt that concepts of research were difficult to understand. Significant association was found between attitudes and level of education of the participants.

Valarie $\mathrm{W}$ et al. conducted a study on perceptions and experiences of nurses undertaking research in the clinical setting. ${ }^{6}$ The results reveal that nurses frequently reported difficulties in being able to conduct research in the clinical area. Dissemination via publication was rare. Personal sacrifices were common and nurses felt that these were not recognized by managers. Nurses undertaking research need more structured support systems and recognition of the value of nursing research. Researchers recommended that individualized help from more experienced researchers are important to improve the situation.

A study conducted by Meenakshi $\mathrm{M}$ to assess the barriers to research utilization among registered nurses working in a tertiary care hospital of Mumbai, revealed that highest barrier of research utilization was insufficient time for research work, followed by the inadequate facilities for research implementation. ${ }^{7}$ Researcher has recommended that administrative support to be extended to nurses in order to translate research findings into practice.

As nurses are at the front line of patient care, they are able to identify gaps in clinical practice and develop ideas and strategies for improving the healthcare needs of patients. So, it is essential that nurses are encouraged to undertake nursing research to provide them with the opportunity to address the issues they see in clinical practice

\section{Objectives}

The objectives of the study were:

- To study attitude towards research among randomly selected professional registered nurses.

- To find out the association between attitude towards research and publication of research article.

- To find out the association between attitude towards research and selected demographic variables.

\section{Materials and Methods}

A descriptive cross-sectional study was conducted among 50 nurses from a quaternary care hospital in Delhi NCR in Dec 2017. The study included nurses of age group 25 to 50 years with minimum two years of experience in clinical or teaching field. Nurses in administrative job were excluded from the study.

The tool consisted of an attitude scale with 20 items. A five-point rating scale was used ranging from strongly agree, agree, uncertain, disagree and strongly disagree to evaluate the attitude of the nursing officers towards research and to identify the contributing factors. The nurses were selected by random sampling technique and rating scale was distributed. Subjects were given 30 minutes to rate the tool. Analysis of data was done by descriptive and inferential statistics. Demographic variables like professional qualification of nurses, years of experience, research studies conducted research publications were described by tables and graphs. Chi square test was used to find the association between attitude of nurses towards research and selected demographic variables. 


\section{Results}

Table 1.Qualification of nurses

\begin{tabular}{|c|c|c|}
\hline Qualification & No. of nurses & Percentage \\
\hline GNM & 14 & $28 \%$ \\
\hline BSc nursing & 20 & $40 \%$ \\
\hline PBBSc nursing & 4 & $08 \%$ \\
\hline MSc nursing & 12 & $24 \%$ \\
\hline
\end{tabular}

Table 1 depicts that out of the total sample, 14 were GNM, 20 were graduates, 4 were graduates with PBBSc nursing and 12 were MSc Nurses. There was an equal distribution of sample in regard to the professional qualification.

As regard to the place of working majority (74\%) of the nurses were posted at clinical area and $26 \%$ were nurse educators.

Table 2.Distribution of Nurses as per years of experience

$(\mathrm{N}=50)$

\begin{tabular}{|c|c|c|}
\hline Years of experience & No of nurses & Percentage \\
\hline$<5$ & 17 & 34 \\
\hline 6 to 10 & 14 & 28 \\
\hline 11 to 15 & 7 & 14 \\
\hline 16 to 20 & 9 & 18 \\
\hline$>20$ & 3 & 06 \\
\hline
\end{tabular}

Data presented in Table 2 revealed that 34\% nurses were having less than 5 years of experience, $28 \%$ were in the group of 6 to 10 years of experience, $14 \%$ and $18 \%$ had 11-15 years and 16-20 years of experience respectively.

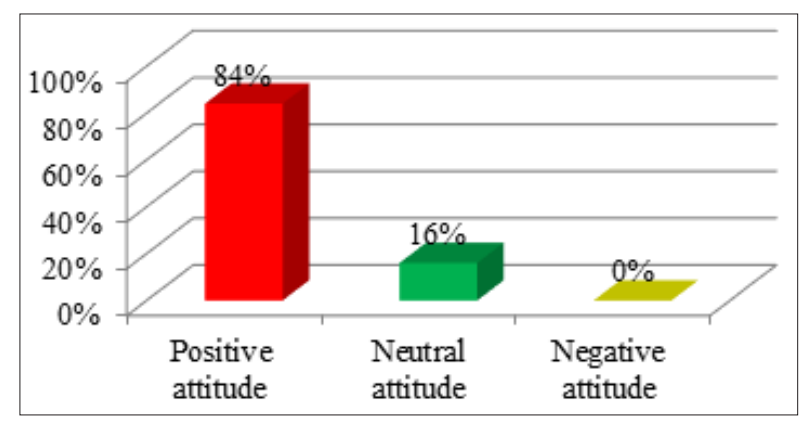

Figure 1.Attitude of the nurses towards research

Data in Figure 1 reflected that majority of the Nurses (84\%) had positive attitude towards research whereas $16 \%$ were neutral towards research. No one was found to have a negative attitude.

Figure 2 indicates that majority of nurses (88\%) did not publish any article in the journal.

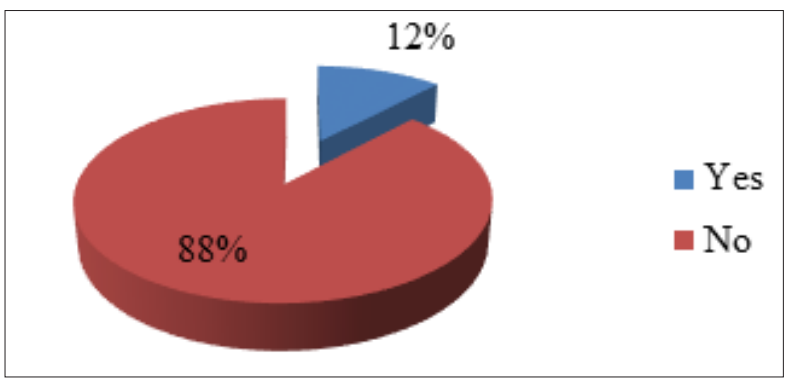

Figure 2.Distribution of sample based on research article publication

Analysis of data further revealed that only $14 \%$ presented paper in conference and $16 \%$ has conducted departmental and Government funded research projects. Only $10 \%$ of nurses conducted individual researches in their area of work.

Chi square statistic was calculated to find out the association between attitude and research publication. The result revealed no significant association as evident from the Chi square value of 0.0023 for $\mathrm{df} 1$ ( $p>0.05)$.

The analysis further revealed that no significant association was found between attitude and professional qualification of the nurses from the Chi square value of 1.0582 for $\mathrm{df}$ 3 ( $p>0.05)$.

\section{Discussion}

The present study reflects that in spite of having positive attitude towards research, very minimal number of nurses is participating in any form of research work. And also, it is important to note that, the nurses who are doing researches in their area of work are not publishing it or presenting the research findings in conferences. Majority of the nurses who published article in the journals were nurse educators. Valarie $\mathrm{W}$ et al study ${ }^{6}$ also reveals that the nurses reported difficulty in conducting research in clinical area and the publications were very rare.

The results of this study are consistent with findings of the study conducted by Hofmeister $\mathrm{N}^{3}$ to examine the attitudes of nurses toward research which did not identify differences in the overall attitudes of nurses based on their educational level. In Poreddi $V$ et al study ${ }^{5}$ a significant association was found between attitudes of research utilization and level of education of the participants.

A study conducted by Elizabeth $\mathrm{S}$ et al. ${ }^{8}$ states that it can be difficult to involve clinical nurses in research. Nursing leadership can act as role models and provide mentorship in research activities for clinical nursing staff. 
Organizations can increase the clinical nurse's participation in nursing research through involving nurses in the institutional review board, allowing clinical nurses to act as principal investigators on research studies, and creating nursing councils to help conduct scientific pre-review of research protocols. ${ }^{9}$

To encourage research initiative the following suggestions were made:

A post for Nodal officer to be created at all tertiary care hospitals to encourage research activities among nurses. A crash course on Research methodology to be arranged for the Nurses on regular basis. Adequate administrative support to be given to the Nurses undertaking departmental projects especially during data collection. Nurses to be encouraged to undertake more clinical research to improve quality of patient care and some form of incentive to be awarded for quality research work.

Researches towards preventive health aspects need to be encouraged as there is paradigm shift in the concept of health and health seeking behavior. Journal club to be established in every hospital to discuss about evidencebased nursing practices. Participation in Journal club to be made compulsory for all Nurses to create an awareness regarding recent researches.

\section{Conclusion}

Nurses need to grow continuously to keep pace with their counterparts in the health care industry. Development of any profession should be in consonance with adoption of scientific approach as it provides perspectives to reality.

Having leadership support, both at the organizational level from the chief executive officer (CEO) and nursing level from the chief nursing officer (CNO) is necessary for success. To fulfill the accountability towards our patients, nurses need to be research oriented. Research should be pivotal in stimulating new vision and exploring new knowledge

\section{Conflict of Interest: None}

\section{References}

1. Polit DF, Beck CT. Nursing research generating and assessing evidence for nursing practice. $10^{\text {th }} \mathrm{Ed}$. Wolters Kluwer, New Delhi. 2016.

2. Mehrdad N, Salsali M, Kazemnejad A. The spectrum of barriers to and facilitators of research utilization in Iranian nursing. Journal of Clinical Nursing 2008; 17(16): 2194-202.

3. Nancee H. Attitudes of nurses toward research. Masters Thesis. 2007. Available from: https:// scholarworks.gvsu.edu/cgi/viewcontent.cgi? article $=1659 \&$ context $=$ theses.

4. Björkström ME, Hamrin EK. Swedish nurses' attitudes towards research and development within nursing. J Adv Nurs 2001; 34(5): 706-14.

5. Poreddi V, Dharma RP, Rohini T et al. Nurses attitudes and perceptions of nursing research: an Indian perspective. Asian J Nur Edu and Research 2014; 4(4): 509-13.

6. Woodward V, Webb C, Prowse M. The perceptions and experiences of nurses undertaking research in the clinical setting. Journal of Research in Nursing 2007; 12(3): 227-44.

7. Meenakshi M. Unpublished Departmental Project. College of Nursing, INHS Asvini Mumbai. 2017

8. Elizabeth $S$, Carrie $P$, Jennifer D. An integrative review of engaging clinical nurses in nursing research. Journal of Nursing Scholarship 2016; 48: 423-30.

9. Balakas K, Bryant T, Jamerson P. Collaborative research partnerships in support of nursing excellence. Nursing Clinics of North America 2011; 46(1): 123-8.

Date of Submission: 2018-07-18 Date of Acceptance: 2018-o9-12 